OPEN ACCESS

Edited by:

Yu Zhang,

Hong Kong University of Science and

Technology, Hong Kong

Reviewed by:

Xiaoliang Yu,

Hong Kong Polytechnic University,

Hong Kong

Kun Rui,

Nanjing Tech University, China

*Correspondence:

Ding Nan

nan1980732@163.com

Specialty section:

This article was submitted to

Electrochemistry,

a section of the journa

Frontiers in Chemistry

Received: 19 September 2020 Accepted: 30 September 2020

Published: 23 October 2020

Citation:

Hua W, Sun H, Ren L and Nan D

(2020) V-Doped CoP Nanosheet

Arrays as Highly Efficient

Electrocatalysts for Hydrogen

Evolution Reaction in Both Acidic and

Alkaline Solutions.

Front. Chem. 8:608133.

doi: 10.3389/fchem.2020.608133

\section{V-Doped CoP Nanosheet Arrays as Highly Efficient Electrocatalysts for Hydrogen Evolution Reaction in Both Acidic and Alkaline Solutions}

\author{
Wei Hua ${ }^{1}$, Huanhuan Sun ${ }^{1}$, Lingbo Ren ${ }^{1}$ and Ding Nan ${ }^{2 \star}$ \\ ' State Key Laboratory of Solidification Processing, Center for Nano Energy Materials, School of Materials Science and \\ Engineering, Northwestern Polytechnical University, Shaanxi Joint Lab of Graphene (Northwestern Polytechnical University), \\ Xi'an, China, ${ }^{2}$ School of Materials Science and Engineering, Inner Mongolia University of Technology, Hohhot, China
}

It is of significant necessity to explore inexpensive and high-active electrocatalysts toward hydrogen evolution reaction (HER) in both acidic and basic media. In this work, V-doped CoP nanosheet arrays supported on the carbon cloth (V-CoP/CC) are fabricated though a facile water-bath/phosphorization method. The nanoarray structure on the three-dimensional self-supporting electrode can provide a large electrochemical active surface area with more exposed active sites to accelerate the reaction kinetics. Furthermore, $\mathrm{V}$ doping is able to tune the electronic properties and thus enhance the intrinsic catalytic activity of CoP. Consequently, the V-CoP/CC electrode exhibits excellent electrocatalytic activities toward $\mathrm{HER}$ in both $0.5 \mathrm{M} \mathrm{H}_{2} \mathrm{SO}_{4}$ and $1 \mathrm{M} \mathrm{KOH}$ solutions with small overpotentials of 88 and $98 \mathrm{mV}$ at a current density of $10 \mathrm{~mA} \mathrm{~cm}-2$, respectively. The present work will offer a feasible way to tailor the catalytic activity by hetero-atoms doping toward HER.

Keywords: hydrogen evolution reaction, V-doped CoP, acid and alkaline solutions, nanosheet arrays, water splitting

\section{INTRODUCTION}

Hydrogen is an effective energy carrier to solve the contemporary energy crisis and environmental pollution (Luo et al., 2014; Seh et al., 2017). Nowadays, hydrogen is still produced mainly from fossil fuels, which suffers from emission of large quantities of carbon dioxide (Zou and Zhang, 2015). Electrolysis of water based on renewable resources is considered as an practical method for producing hydrogen sustainability (Li and Zheng, 2017; Hua et al., 2020). By far, the state-of-the-art electrocatalysts for hydrogen evolution reaction (HER) are still precious Pt-based materials, the scale-up application of which, however, is restricted to their scarcity and high cost. Therefore, the development of low-cost and high-activity electrocatalysts for HER has attracted a wide spread attention.

The earth-abundant transitional metal-based materials, such as alloys (Zhang et al., 2017), oxides (Dong et al., 2019), sulfides (Chen et al., 2019), selenides (Liu et al., 2017), carbides (Lu et al., 2019), nitrides (Yao et al., 2019) and phosphides (Wang J. et al., 2018), have been proved as promising catalysts for HER. Of particular note, more efforts have been made in the design and preparation of transitional metal phosphides (TMPs) as HER catalysts owing to the excellent electrocatalytic performance and long stability in both acidic and alkaline media (Shi and Zhang, 2016; Wang Y. et al., 2017). However, the electrochemical activity of monophase TMPs needs to 
be further improved compared with precious metal-based materials. HER occurs at the surfaces of electrocatalysts, hence, increasing the number of active sites is of great benefit in improving the catalytic performance. Notably, the array architecture combined with a bind-free three-dimensional (3D) self-supporting electrodes displays much better HER properties than the planar electrodes due to the more accessible active sites (Wang Y. et al., 2018). Moreover, hetero-atom doping has been an effective method to improve the performance of electrocatalysts. For example, Pan et al. (2016) investigated the doping effect of $\mathrm{Fe}, \mathrm{Ni}$, and $\mathrm{Cu}$ elements on the catalytic properties of the $\mathrm{Co}_{2} \mathrm{P}$ catalysts. Electrochemical results show
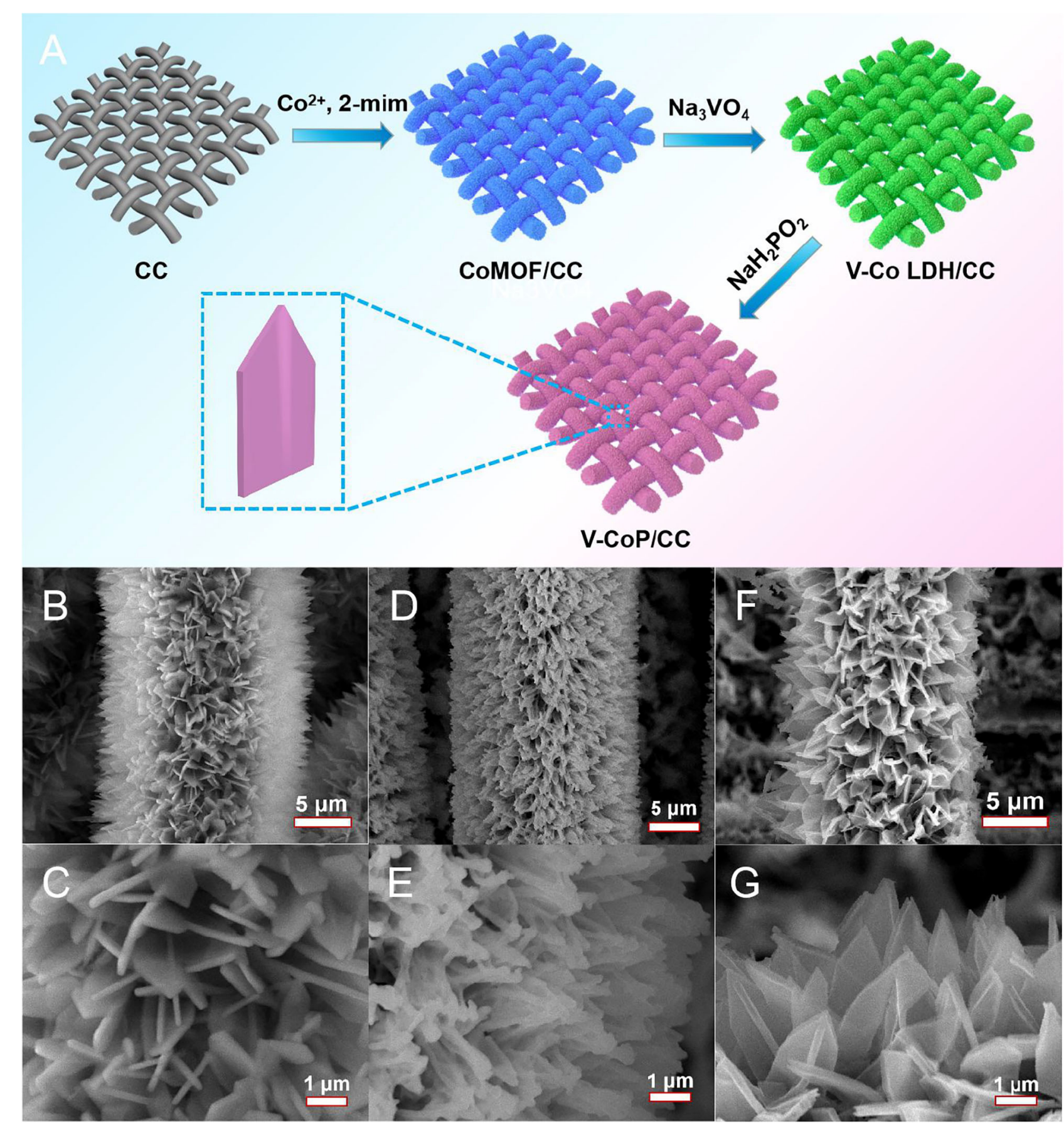

FIGURE 1 | (A) Schematic illustration of the fabrication process of V-CoP nanosheet arrays on the CC. SEM images of CoMOF (B,C), V-Co LDH (D,E), V-CoP (F,G) on the CC. 
that the electrocatalytic performance for HER follows the trend of $\mathrm{Fe}-\mathrm{Co}_{2} \mathrm{P}>\mathrm{Ni}-\mathrm{Co}_{2} \mathrm{P}>\mathrm{Cu}-\mathrm{Co}_{2} \mathrm{P}$ in the acidic solution, which is related to the difference of morphology, and electronic structure after doping. Recently, Wang's group reported a $\mathrm{Bi} / \mathrm{CoP}$ sample with a flower-like structure (Guo et al., 2020). The theoretical calculation revealed that $\mathrm{Bi}$ doping could tune the hydrogen binding energy of $\mathrm{CoP}$, enabling the $\mathrm{Bi} / \mathrm{CoP}$ electrode to display high electrocatalytic properties for HER in both alkaline and acidic media. In addition, doping with various metal elements, such as Er (Zhang et al., 2019), Al (Du et al., 2018), Mo (Guan et al., 2018), etc., has been reported with enhanced electrocatalytic activities. To our knowledge, the $\mathrm{V}$ doping in TMPs has barely been reported. Therefore, it is highly imperative to design and investigate the effect of $\mathrm{V}$ doping on the performance for HER.

Herein, the influence of $\mathrm{V}$ doping on the electrocatalytic activity of CoP toward HER is investigated and identified in both acidic and basic media. The V-doped CoP nanosheet arrays grown on carbon cloth (CoP/CC) have been prepared though a facile water bath/phosphorization approach. Owing to the $3 \mathrm{D}$ conductive $\mathrm{CC}$ substrate, nanosheet array structure, and the optimized electronic structure by $\mathrm{V}$ doping, CoP/CC exhibits much enhanced electrocatalytic HER activity with low overpotentials of 88 and $98 \mathrm{mV}$ at $10 \mathrm{~mA} \mathrm{~cm}$ cm $^{-2}$ in $0.5 \mathrm{M}$ $\mathrm{H}_{2} \mathrm{SO}_{4}$ and $1 \mathrm{M} \mathrm{KOH}$, respectively. The excellent performance indicates that $\mathrm{V}$ doping is an efficient strategy to improve the performance of HER electrocatalysts in both acidic and alkaline solutions.

\section{EXPERIMENTAL SECTION}

\section{Materials Synthesis}

Prior to synthesis, a piece of carbon cloth was treated in $6 \mathrm{M}$ nitric acid at $85^{\circ} \mathrm{C}$ overnight. For the preparation of cobaltbased metal-organic frameworks on CC (CoMOF/CC), $2 \mathrm{mmol}$ cobalt (II) nitrate hexahydrate $\left[\mathrm{Co}\left(\mathrm{NO}_{3}\right)_{2} \cdot 6 \mathrm{H}_{2} \mathrm{O}\right]$ and $16 \mathrm{mmol}$ 2-methylimidazole (2-mim) were dispersed in $40 \mathrm{ml}$ deionized water (18.2 M $\Omega$ ), respectively. Then the homogeneous aqueous solution of 2 -mim was added into the $\mathrm{Co}\left(\mathrm{NO}_{3}\right)_{2}$ solution and a piece of treated CC was put into the above mixture for $2 \mathrm{~h}$ at room temperature. For the synthesis of V-Co layered double hydroxide $(\mathrm{LDH})$, the as-prepared CoMOF was immersed into $50 \mathrm{ml}$ water/ethanol solution (4:1 in volume) containing $100 \mathrm{mg}$ sodium orthovanadate $\left(\mathrm{Na}_{3} \mathrm{VO}_{4}\right)$, then it reacted at $50^{\circ} \mathrm{C}$ for $20 \mathrm{~min}$. Finally, the V-Co LDH grown on the CC and $0.2 \mathrm{~g}$ $\mathrm{NaH}_{2} \mathrm{PO}_{2}$ placed at the middle of tube furnace, with $\mathrm{NaH}_{2} \mathrm{PO}_{2}$ at the upstream side, which were then heated to $350^{\circ} \mathrm{C}$ with a ramping rate of $2^{\circ} \mathrm{C} \mathrm{min}^{-1}$ under Ar flow and kept for $2 \mathrm{~h}$. The mass loading of the as-synthesized V-CoP is about $2.4 \mathrm{mg} \mathrm{cm}^{-2}$. For the preparation of hollow CoP, CoMOF was annealed for $1 \mathrm{~h}$ at $300^{\circ} \mathrm{C}$ with a heating rate of $1^{\circ} \mathrm{C} \mathrm{min}{ }^{-1}$ under air conditions and then the phosphidation procedure was similar to that of $\mathrm{V}$-CoP. The mass loading of CoP is about $2 \mathrm{mg} \mathrm{cm}^{-2}$.

\section{Materials Characterization}

Field-emission scanning electron microscopy (SEM, FEI NanoSEM 450) and transmission electron microscopy (TEM,

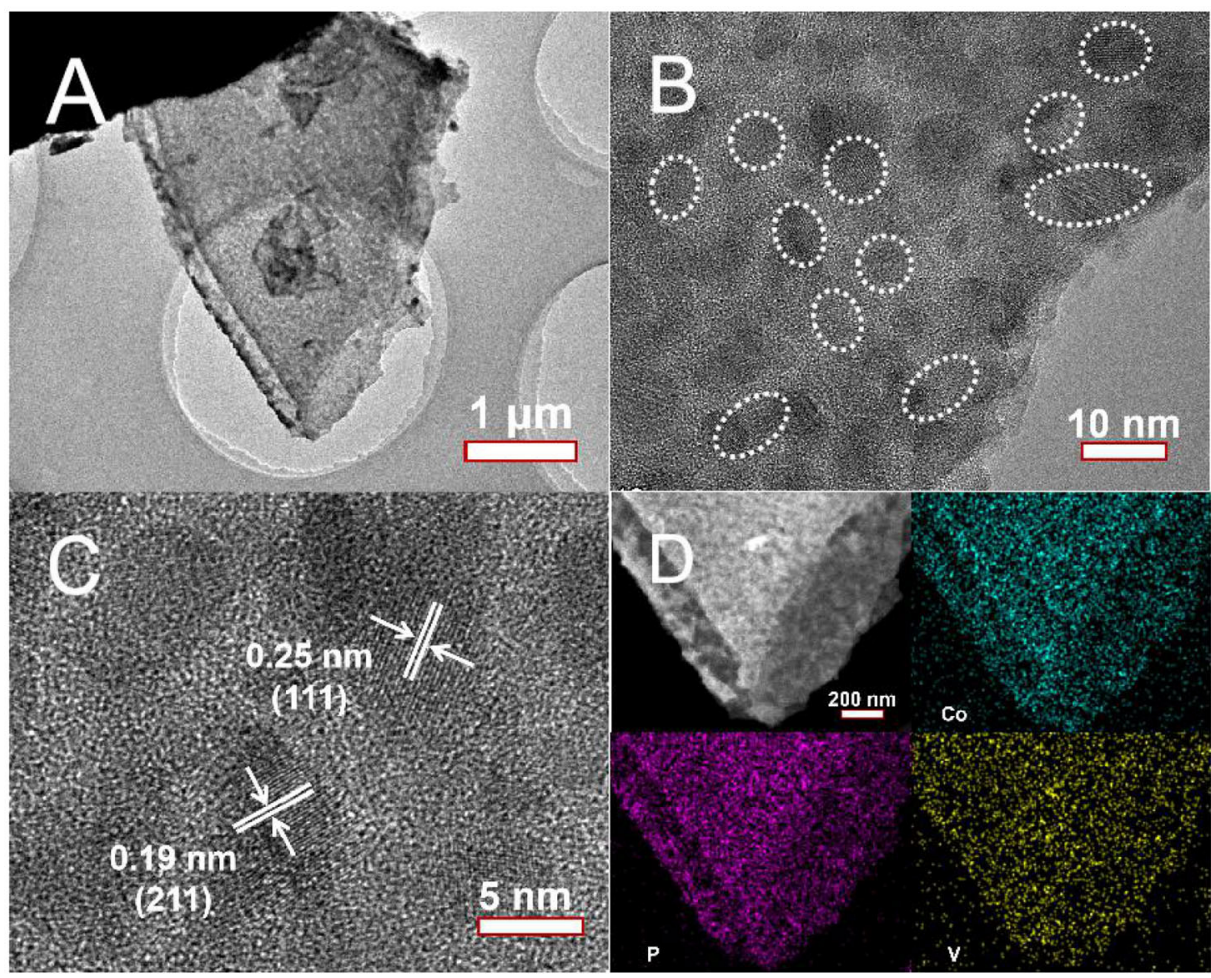

FIGURE 2 | (A,B) TEM and (C) HRTEM images of V-CoP/CC, (D) HAADF-STEM image of V-CoP/CC and EDS elemental mappings of Co, P, and V elements. 
FEI Talos F200X) were used to study the morphology and structure of the as-synthesized samples. The phased structure was identified by X-ray diffraction (XRD, Shimadzu XRD-7000).

\section{Electrochemical Evaluation}

Electrochemical performance of the electrodes was tested on an electrochemical workstation (CHI 660E). The as-received samples and carbon rod were served as the working electrode and counter electrode, respectively. The reference electrodes were $\mathrm{Hg} / \mathrm{HgO}$ electrode and saturated calomel electrode (SCE) in $1.0 \mathrm{M} \mathrm{KOH}(\mathrm{pH}=13.8)$ and $0.5 \mathrm{M} \mathrm{H}_{2} \mathrm{SO}_{4}(\mathrm{pH}=0.6)$, respectively. Polarization curves were tested by linear sweep voltammetry (LSV) at $2 \mathrm{mV} \mathrm{s}^{-1}$, and the potential values were calibrated to reversible hydrogen electrodes (RHE) with IRcorrection, $\mathrm{E}_{\mathrm{RHE}}=\mathrm{E}_{\mathrm{Hg} / \mathrm{HgO}(\mathrm{SCE})}+0.097+0.059 \mathrm{pH}$. The IRcorrection was conducted by $\mathrm{E}_{\text {Corrected }}=\mathrm{E}_{\mathrm{Raw}}$ - IRs, here, Rs corresponds to the series resistance, which can be obtained from the electrochemical impedance spectrum (EIS) measurements. The durability of the sample was studied by chronopotentiometry method at a constant current density of $10 \mathrm{~mA} \mathrm{~cm}^{-2}$ and cyclic voltammetry $(\mathrm{CV})$ at a scan rate of $50 \mathrm{mV} \mathrm{s}^{-1}$ for 2,000 cycles. EIS was measured at $-0.1 \mathrm{~V}$ vs. RHE in the frequency range between $0.1 \mathrm{~Hz}$ and $100 \mathrm{KHz}$ with an $\mathrm{AC}$ amplitude of $5 \mathrm{mV}$. CV measurement was tested in the potential range from
0.15 to $0.25 \mathrm{~V}$ vs. RHE at various scan rates to estimate the electrochemical active surface area (ECSA).

\section{RESULTS AND DISCUSSIONS}

The preparation process of the $\mathrm{V}$-CoP/CC electrode is schematically illustrated in Figure 1A. Firstly, CoMOF nanosheet arrays are uniformly grown on the surface of the carbon cloth via a simple aqueous solution reaction between $\mathrm{Co}^{2+}$ and 2-mim at room temperature (Fang et al., 2016). The SEM images (Figures 1B,C) show the uniform CoMOF nanosheet arrays supported on the CC. Secondly, the as-synthesized CoMOF precursor was immersed into a $\mathrm{Na}_{3} \mathrm{VO}_{4}$ solution. Owing to the hydrolysis of the solution, the hydrogen ions generated enhanced the etch of CoMOF and release Co ions, at the same time, the local $\mathrm{pH}$ increased, making $\mathrm{V}$ and Co precipitate on its surface to form V-Co LDH (Figures 1D,E). Finally, the V$\mathrm{CoP} / \mathrm{CC}$ was obtained through a typical phosphidation process. Remarkably, as shown in Figures 1F,G, the as-prepared V-CoP well-retain the nanoarray architecture on the CC. Similarly, $\mathrm{CoP}$ maintains the original morphology after phosphidation (Supplementary Figures 1A,B).

To further investigate the microstructure, the $\mathrm{V}$-CoP nanosheets are characterized by TEM imaging. As displayed

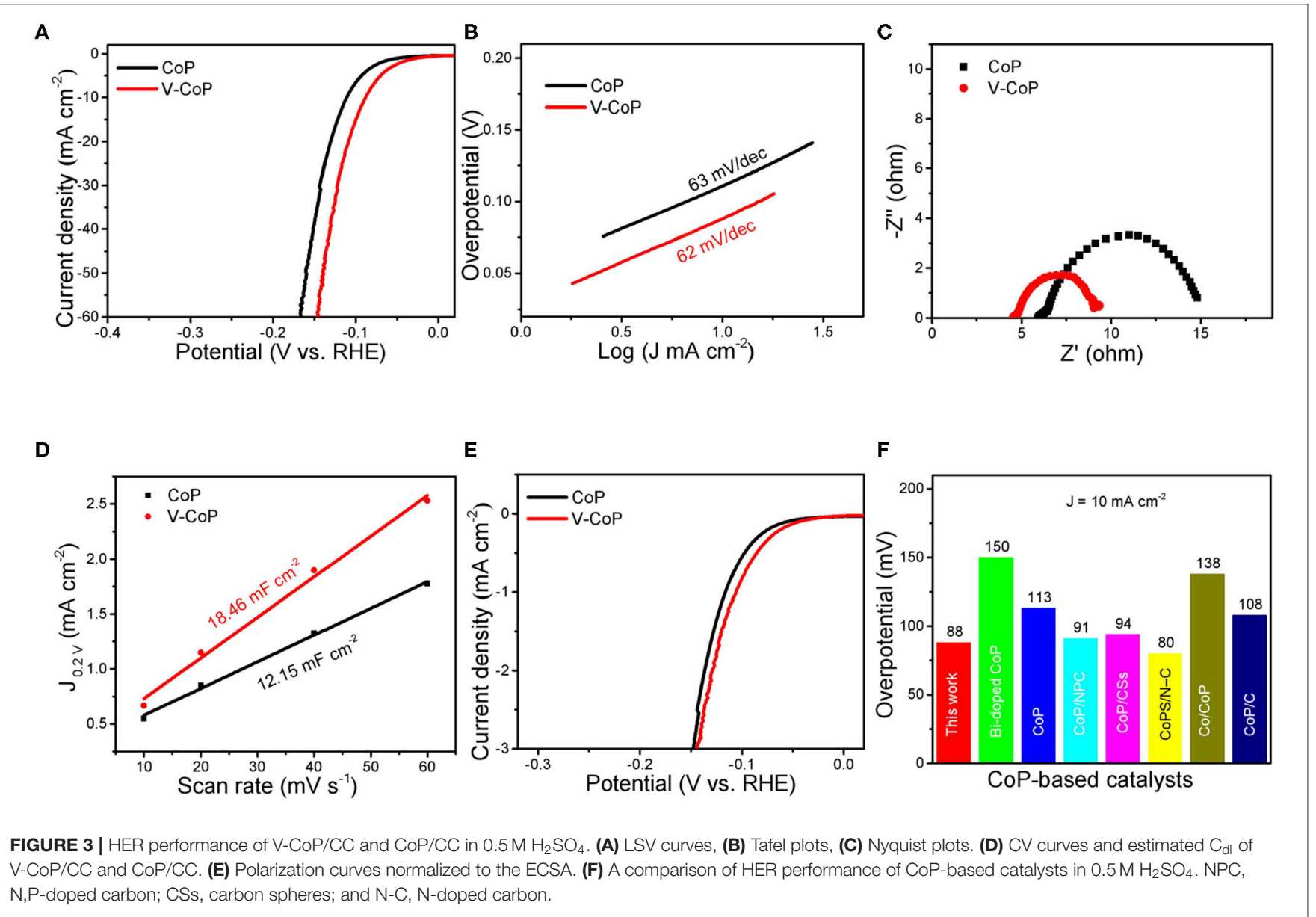


in Figure 2A, the V-CoP exhibits a thin nanosheet structure. Figure 2B reveals that the nanosheet is consisted of numerous ultrafine crystalline nanoparticles and amorphous components. The HRTEM image (Figure 2C) shows distinct crystal spacings of $0.25 \mathrm{~nm}$ and $0.19 \mathrm{~nm}$ on the nanoparticles, which are indexed to the (111) and (211) facets of CoP, respectively (Wang et al., 2019). Moreover, the specific feature of V-CoP nanosheet is further examined by HAADF-STEM and energy dispersive spectrometer (EDS) elemental mapping (Figure 2D). The EDS mapping result demonstrates the homogeneous distribution of Co, $\mathrm{P}$ and $\mathrm{V}$ elements, indicating that $\mathrm{V}$ element is uniformly doped in CoP and the atomic ratio of V:Co is determined to be about $0.23: 1$. The phase structures of the as-synthesized $\mathrm{V}-\mathrm{CoP} / \mathrm{CC}$ and CoP/CC are analyzed by XRD. As displayed in Supplementary Figure 2, apart from the two diffraction peaks corresponding to the CC substrate (Guan et al., 2017), there are no other distinct diffraction peaks. The phenomenon is consistent with the result of TEM that the sample is made up of ultrathin nanoparticles and amorphous components.

The results of the above characterization indicate that $\mathrm{V}$ doped CoP nanosheet arrays on the CC are successfully prepared. The electrocatalytic HER performance of the sample in the acidic solution is first investigated. As displayed in Figure 3A, the $\mathrm{CoP} / \mathrm{CC}$ requires an overpotential of $111 \mathrm{mV}$ to afford the current density of $10 \mathrm{~mA} \mathrm{~cm}{ }^{-2}$, whereas V-CoP/CC only needs $88 \mathrm{mV}$ to produce the same current density. The Tafel slopes are further calculated to study the HER mechanism on the electrocatalysts (Figure 3B). The Tafel slopes of $\mathrm{CoP} / \mathrm{CC}$ and $\mathrm{V}-\mathrm{CoP} / \mathrm{CC}$ are 62 and $63 \mathrm{mV} / \mathrm{dec}$, respectively. The similar values indicate that the hydrogen evolution on the two samples follows the same Volmer-Heyrovsky mechanism. To study the kinetics of the catalysts, charge transfer resistances $\left(\mathrm{R}_{\mathrm{ct}}\right)$ have been characterized by EIS at $-0.1 \mathrm{~V}$ vs. RHE. As shown in Figure $3 \mathrm{C}$, the $\mathrm{V}-\mathrm{CoP} / \mathrm{CC}$ manifests a smaller value of $\mathrm{R}_{\mathrm{ct}}(4.6 \Omega)$ than that of CoP/CC $(9 \Omega)$, indicating a faster reaction kinetics (Sun et al., 2020). To further understand the reason for the higher elecreocatalytic activity of $\mathrm{V}-\mathrm{CoP} / \mathrm{CC}$, the electrochemical double layer capacitances $\left(\mathrm{C}_{\mathrm{dl}}\right)$ is measured by $\mathrm{CVs}$ with various scanning rates in the potential range between 0.15 and $0.25 \mathrm{~V}$ vs. RHE (Supplementary Figures 3A,B). As observed in Figure 3D, the V-CoP/CC electrode shows a bigger $\mathrm{C}_{\mathrm{dl}}\left(18.46 \mathrm{mF} \mathrm{cm}^{-2}\right)$ than CoP/CC (12.15 $\mathrm{mF} \mathrm{cm}^{-2}$ ), suggesting that $\mathrm{V}-\mathrm{CoP} / \mathrm{CC}$ has higher ECSA and is able to expose more active sites during the reaction process. To investigate the intrinsic activity of $\mathrm{V}$ $\mathrm{CoP} / \mathrm{CC}$, the polarization curves are further normalized to the ECSA (Figure 3E). Notably, the V-CoP/CC displays much higher current density than $\mathrm{CoP} / \mathrm{CC}$, indicating that $\mathrm{V}$ doping can improve the intrinsic catalytic activity of CoP (Liang et al., 2016). The aforementioned results show that $\mathrm{V}$ doping can not only increase the number active sites, but also optimize the electronic structure of $\mathrm{CoP}$ and improve the intrinsic catalytic activity, thus exhibiting the enhanced catalytic performance toward HER in acidic media. It is worth to note that the HER performance of the present $\mathrm{V}$-CoP/CC electrode outperforms those of most reported
A

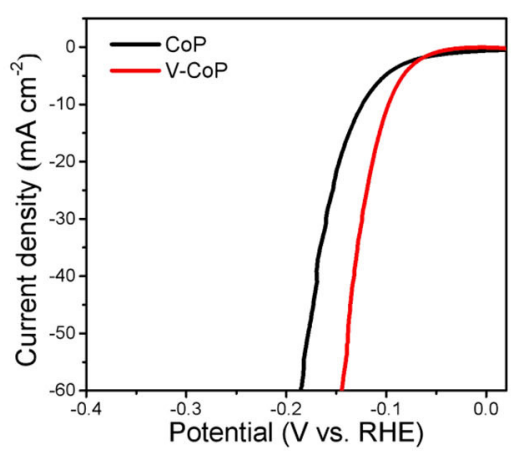

D

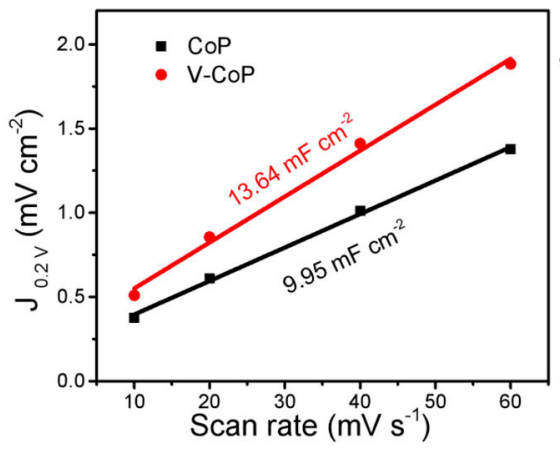

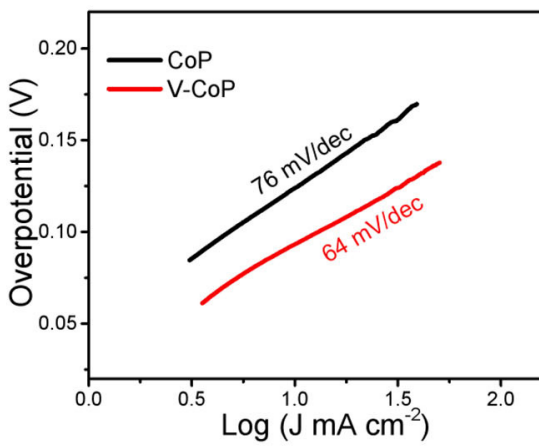

E

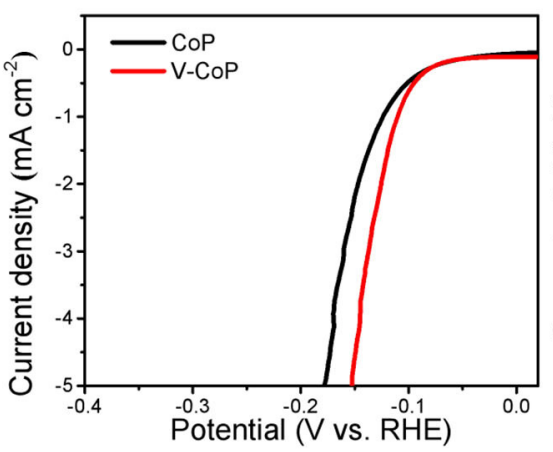

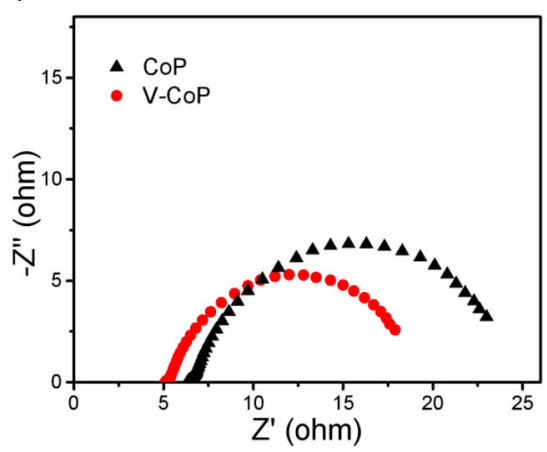

$\mathbf{F}$

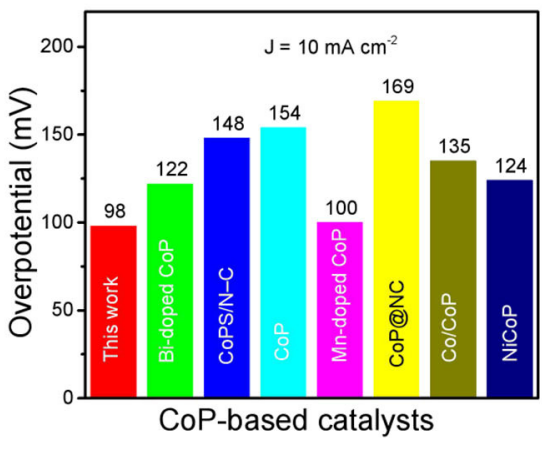

FIGURE 4 | HER performance of V-CoP/CC and CoP/CC in $1 \mathrm{M} \mathrm{KOH}$. (A) LSV curves. (B) Tafel plots. (C) Nyquist plots. (D) The estimated $\mathrm{C}_{\mathrm{dl}}$ of V-CoP/CC and CoP/CC. (E) Polarization curves normalized to the ECSA. (F) A comparison of HER activities of CoP-based catalysts in $1 \mathrm{M}$ KOH. NC, nitrogen-doped porous carbon. 
A

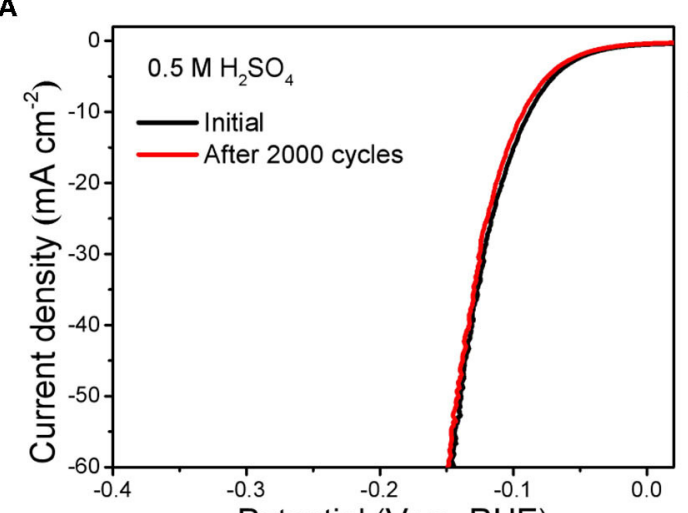

C

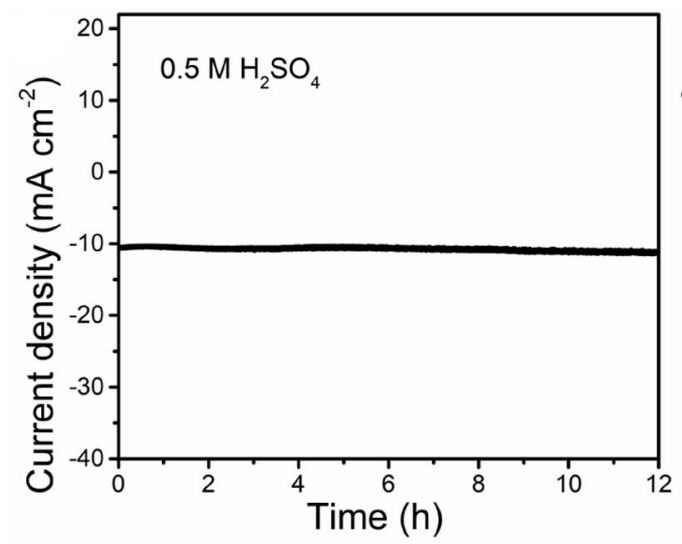

B

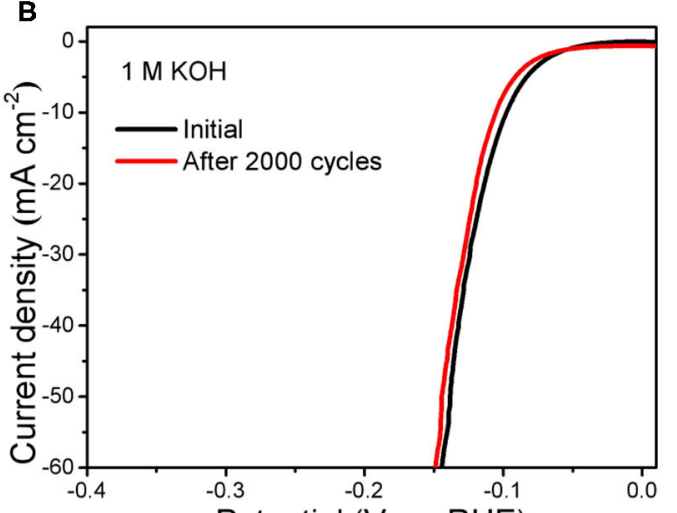

D

Potential (V vs. RHE)

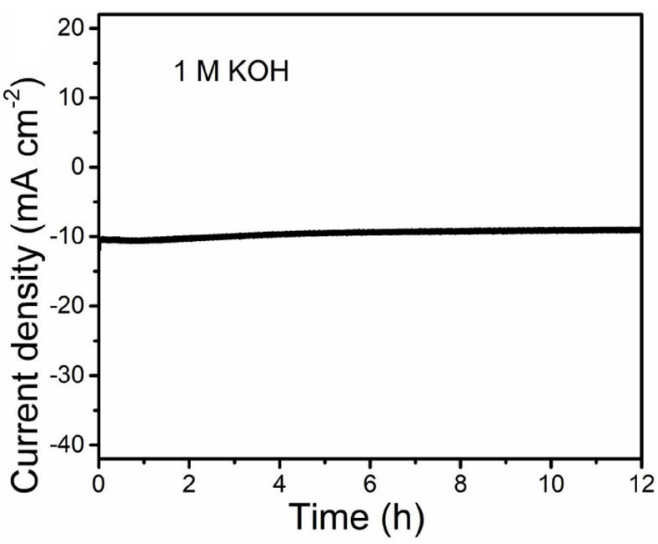

FIGURE 5 | Polarization curves of V-CoP/CC initially and after 2,000 CV cycles (A,B) and time-dependent current density curves (C,D) in 0.5 M $\mathrm{H}_{2}$ SO ${ }_{4}$ and $1.0 \mathrm{M}$ $\mathrm{KOH}$, respectively.

CoP-based catalysts in acidic solution, as shown in Figure 3F (Luo et al., 2017; Wang H. et al., 2017; Li H. et al., 2018; Li, Y et al., 2018; Gao et al., 2019; Huang et al., 2019).

The V-CoP/CC electrode has shown enhanced electrocatalytic performance for HER in acidic media. Meanwhile, water-alkali electrolyzer needs active and low-cost electrocatalysts that can work well in basic condition. As shown in Figure 4A, the VCoP/CC also displays good catalytic performance toward HER in $1 \mathrm{M} \mathrm{KOH}$ solution, reaching the current density of $10 \mathrm{~mA}$ $\mathrm{cm}^{-2}$ with a small overpotential of $98 \mathrm{mV}$. By contrast, the CoP/CC electrode requires a higher overpotential of $124 \mathrm{mV}$ to obtain the current density of $10 \mathrm{~mA} \mathrm{~cm}$. Tafel slopes are also employed to investigate the reaction kinetics in basic media. The Tafel slopes of $\mathrm{V}-\mathrm{CoP} / \mathrm{CC}$ and $\mathrm{CoP} / \mathrm{CC}$ electrodes are 64 and $76 \mathrm{mV} / \mathrm{dec}$, respectively (Figure 4B). The value of $\mathrm{V}-\mathrm{CoP} / \mathrm{CC}$ is similar with that of the electrode in acidic media, while CoP/CC exhibits higher Tafel slope in $1 \mathrm{M} \mathrm{KOH}$, suggesting that $\mathrm{V}$-doping can improve the water dissociation process and accelerate the reaction kinetics in alkaline condition. In line with this result, as displayed in Figure 4C, the $\mathrm{V}$ CoP/CC shows a smaller $\mathrm{R}_{\mathrm{ct}}(13.9 \Omega)$ than $\mathrm{CoP} / \mathrm{CC}(18.3 \Omega)$. The CVs (Supplementary Figures 4A,B) in $0.15-0.25 \mathrm{~V}$ vs. RHE are also tested to calculate the $\mathrm{C}_{\mathrm{dl}}$ (Figure $4 \mathrm{D}$ ). The $\mathrm{C}_{\mathrm{dl}}$ value of $\mathrm{V}-\mathrm{CoP} / \mathrm{CC}$ is $13.64 \mathrm{mF} \mathrm{cm} \mathrm{cm}^{-2}$, which is higher than that of $\mathrm{CoP} / \mathrm{CC}\left(9.96 \mathrm{mF} \mathrm{cm}^{-2}\right)$. The current density is also normalized to the corresponding ECSA, the property of $\mathrm{V}-\mathrm{CoP} / \mathrm{CC}$ is still superior to $\mathrm{CoP} / \mathrm{CC}$ (Figure 4E). It is worth to note that, when normalized to ECSA, the performance difference between $\mathrm{CoP}$ and $\mathrm{V}$-CoP is larger in alkaline than in acidic electrolyte. HER in basic media is not only dominated by the binding energy of hydrogen, but also depends on the water dissociation step. The larger difference indicate that $\mathrm{V}$ doping can efficiently accelerate the water dissociation process, and thus $\mathrm{V}$-CoP exhibits much better intrinsic catalytic activity. The result reveals that the $\mathrm{V}-\mathrm{CoP} / \mathrm{CC}$ electrode shows not only more active sites but also the higher intrinsic catalytic activity than CoP/CC. Remarkably, the present performance is at the top level among the previous reported CoP-based samples, as summarized in Figure 4F (Li et al., 2017; Ge et al., 2018).

To evaluate the stability of $\mathrm{V}$-CoP/CC in both acidic and basic solutions, long-term $\mathrm{CV}$ scanning is performed for 2,000 cycles. As displayed in Figure 5A, the polarization curves of the electrodes before and after the cycling test are almost overlapped under the acidic condition. As for the alkaline solution, only $8 \mathrm{mV}$ negative shift is observed 
after the 2,000-cycling at the current density of $10 \mathrm{~mA} \mathrm{~cm}^{-2}$ (Figure 5B). In addition, the current density-time tests are carried out to explore the stability of the $\mathrm{V}-\mathrm{CoP} / \mathrm{CC}$ electrode. As shown in Figures $\mathbf{5 C , D}$, the current density expresses a negligible decay during a 24-h durability test in $1 \mathrm{M} \mathrm{KOH}$, while there is barely change in the current density during the measurement in $0.5 \mathrm{M} \mathrm{H} \mathrm{H}_{2} \mathrm{SO}_{4}$. The above results show that the material has excellent stability in acidic media, and the performance has only a small attenuation under alkaline condition, which is mainly due to the generated corresponding hydroxides on the surface (Zhang et al., 2018; Lwu et al., 2019).

\section{CONCLUTIONS}

In summary, a novel $\mathrm{V}$-CoP nanosheet array grown on the CC skeleton has been successfully synthesized though a facile method. The $\mathrm{V}$ doping poses a positive effect on the electrocatalytic performance for HER under both acidic and alkaline conditions. The optimized electronic property by $\mathrm{V}$ doping is of great benefit in increasing the intrinsic catalytic activity of CoP. In addition, the nanoarray architecture is of great benefit for offering more accessible catalytic active sites. As a result, the $\mathrm{V}-\mathrm{CoP} / \mathrm{CC}$ electrode only requires small overpotentials of 88 and $98 \mathrm{mV}$ to reach the current density of $10 \mathrm{~mA} \mathrm{~cm}^{-2}$ in acidic and basic media, respectively. The present hetero-atom doping strategy would offer a new window for rationally designing high active catalysts toward HER.

\section{REFERENCES}

Chen, X., Wang, Z., Wei, Y., Zhang, X., Zhang, Q., Gu, L., et al. (2019). High phase-purity $1 \mathrm{~T}-\mathrm{MoS}_{2}$ ultrathin nanosheets by a spatially confined template. Angew. Chem. Int. Ed. 58, 17621-17624. doi: 10.1002/anie.201 909879

Dong, Z., Lin, F., Yao, Y., and Jiao, L. (2019). Crystalline $\mathrm{Ni}(\mathrm{OH})_{2} /$ amorphous $\mathrm{NiMoO}_{\mathrm{x}}$ mixed catalyst with Pt-like performance for hydrogen production. Adv. Energy Mater. 9:1902703. doi: 10.1002/aenm.201902703

Du, H., Xia, L., Zhu, S., Qu, F., and Qu, F. (2018). Al-doped $\mathrm{Ni}_{2} \mathrm{P}$ nanosheet array: a superior and durable electrocatalyst for alkaline hydrogen evolution. Chem. Commun. 54, 2894-2897. doi: 10.1039/C7CC09445K

Fang, G., Zhou, J., Liang, C., Pan, A., Zhang, C., Tang, Y., et al. (2016). MOFs nanosheets derived porous metal oxide-coated three-dimensional substrates for lithium-ion battery applications. Nano Energy 26, 57-65. doi: 10.1016/j.nanoen.2016.05.009

Gao, S., Yang, M., Li, S., Xia, J., Mei, J., Xie, S., et al. (2019). A phosphorusdoped carbon sphere supported CoP nanocatalyst for electrochemical hydrogen evolution. Sustain. Energy Fuels 3, 823-830. doi: 10.1039/C8SE0 $0498 \mathrm{~F}$

Ge, Y., Chen, J., Chu, H., Dong, P., Craig, S. R., Ajayan, P. M., et al. (2018). Urchin-like CoP with controlled manganese doping toward efficient hydrogen evolution reaction in both acid and alkaline solution. ACS Sustain. Chem. Eng. 6, 15162-15169. doi: 10.1021/acssuschemeng.8b03638

Guan, C., Liu, X., Elshahawy, A. M., Zhang, H., Wu, H., Pennycook, S. J., et al. (2017). Metal-organic framework derived hollow $\mathrm{CoS}_{2}$ nanotube arrays: an efficient bifunctional electrocatalyst for overall water splitting. Nanosc. Horiz. 2, 342-348. doi: 10.1039/C7NH00079K

\section{DATA AVAILABILITY STATEMENT}

All datasets generated for this study are included in the article/Supplementary Material.

\section{AUTHOR CONTRIBUTIONS}

WH carried out experiments and wrote the paper. HS performed and analyzed experimental results. LR carried out experiments. DN designed experiments and contributed to writing the paper. All authors contributed to the article and approved the submitted version.

\section{FUNDING}

This work was supported by the National Natural Science Foundation of China (51772249 and 51821091), Fundamental Research Funds for the Central Universities (G2017KY0308 and 3102019JC005), Natural Science Foundation (2019JLM-26), Innovation Program for Talent (2019KJXX-066), and Post-doctoral Program of Shaanxi Province (2018BSHTDZZ16). The authors also thank the Analytical \& Testing Center of Northwestern Polytechnical University for TEM analysis.

\section{SUPPLEMENTARY MATERIAL}

The Supplementary Material for this article can be found online at: https://www.frontiersin.org/articles/10.3389/fchem. 2020.608133/full\#supplementary-material

Guan, C., Xiao, W., Wu, H., Liu, X., Zang, W., Zhang, H., et al. (2018). Hollow Mo-doped CoP nanoarrays for efficient overall water splitting. Nano Energy 48, 73-80. doi: 10.1016/j.nanoen.2018.03.034

Guo, L., Bai, X., Xue, H., Sun, J., Song, T., Zhang, S., et al. (2020). MOF-derived hierarchical 3D Bi-doped CoP nanoflower eletrocatalyst for hydrogen evolution reaction in both acidic and alkaline media. Chem. Commun. 56, 7702-7705. doi: 10.1039/C9CC09684A

Hua, W., Sun, H.-H., Xu, F., and Wang, J.-G. (2020). A review and perspective on molybdenum-based electrocatalysts for hydrogen evolution reaction. Rare Met. 39, 335-351. doi: 10.1007/s12598-020-01384-7

Huang, X., Xu, X., Li, C., Wu, D., Cheng, D., and Cao, D. (2019). Vertical CoP nanoarray wrapped by N,P-Doped carbon for hydrogen evolution reaction in both acidic and alkaline conditions. Adv. Energy Mater. 9:1803970. doi: 10.1002/aenm.201803970

Li, H., Zhao, X., Liu, H., Chen, S., Yang, X., Lv, C., et al. (2018). Sub-1.5 nm ultrathin CoP nanosheet aerogel: efficient electrocatalyst for hydrogen evolution reaction at all pH values. Small 14:1802824. doi: 10.1002/smll.201802824

Li, J., and Zheng, G. (2017). One-dimensional earth-abundant nanomaterials for water-splitting electrocatalysts. Adv. Sci. 4:1600380. doi: 10.1002/advs.201600380

Li, Y., Liu, J., Chen, C., Zhang, X., and Chen, J. (2017). Preparation of NiCoP hollow quasi-polyhedra and their electrocatalytic properties for hydrogen evolution in alkaline solution. ACS Appl. Mater. Interfaces 9, 5982-5991. doi: 10.1021/acsami.6b14127

Li, Y., Niu, S., Rakov, D., Wang, Y., Cabán-Acevedo, M., Zheng, S., et al. (2018). Metal organic framework-derived CoPS/N-doped carbon for efficient electrocatalytic hydrogen evolution. Nanoscale 10, 7291-7297. doi: 10.1039/C8NR01811A 
Liang, H., Gandi, A. N., Anjum, D. H., Wang, X., Schwingenschlogl, U., and Alshareef, H. N. (2016). Plasma-assisted synthesis of NiCoP for efficient overall water splitting. Nano Lett. 16, 7718-7725. doi: 10.1021/acs.nanolett.6b03803

Liu, B., Zhao, Y. F., Peng, H. Q., Zhang, Z. Y., Sit, C. K., Yuen, M. F., et al. (2017). Nickel-cobalt diselenide 3D mesoporous nanosheet networks supported on Ni foam: an all-pH highly efficient integrated electrocatalyst for hydrogen evolution. Adv. Mater. 29:1606521. doi: 10.1002/adma.201606521

Lu, X. F., Yu, L., Zhang, J., and Lou, X. W. D. (2019). Ultrafine dualphased carbide nanocrystals confined in porous nitrogen-doped carbon dodecahedrons for efficient hydrogen evolution reaction. Adv. Mater. 31:1900699. doi: 10.1002/adma.201900699

Luo, B., Huang, T., Zhu, Y., and Wang, D. (2017). Glucose-derived carbon sphere supported $\mathrm{CoP}$ as efficient and stable electrocatalysts for hydrogen evolution reaction. J. Energy Chem. 26, 1147-1152. doi: 10.1016/j.jechem.2017. 08.013

Luo, J., Im, J. H., Mayer, M. T., Schreier, M., Nazeeruddin, M. K., Park, N. G., et al. (2014). Water photolysis at $12.3 \%$ efficiency via perovskite photovoltaics and earth-abundant catalysts. Science 345, 1593-1596. doi: 10.1126/science. 12 58307

Lwu, Z., Huang, L., Liu, H., and Wang, H. (2019). Element-specific restructuring of anion- and cation-substituted cobalt phosphide nanoparticles under electrochemical water-splitting conditions. ACS Catal. 9, 2956-2961. doi: 10.1021/acscatal.8b03835

Pan, Y., Liu, Y., Lin, Y., and Liu, C. (2016). Metal doping effect of the $\mathrm{M}-\mathrm{Co}_{2} \mathrm{P} /$ nitrogen-doped carbon nanotubes $(\mathrm{M}=\mathrm{Fe}, \mathrm{Ni}, \mathrm{Cu})$ hydrogen evolution hybrid catalysts. ACS Appl. Mater. Interfaces 8, 13890-13901. doi: 10.1021/acsami.6b02023

Seh, Z. W., Kibsgaard, J., Dickens, C. F., Chorkendorff, I., Nørskov, J. K., and Jaramillo, T. F. (2017). Combining theory and experiment in electrocatalysis: insights into materials design. Science 355:eaad4998. doi: 10.1126/science.aad4998

Shi, Y., and Zhang, B. (2016). Recent advances in transition metal phosphide nanomaterials: synthesis and applications in hydrogen evolution reaction. Chem. Soc. Rev. 45, 1529-1541. doi: 10.1039/C5CS00434A

Sun, H., Liu, H., Hou, Z., Zhou, R., Liu, X., and Wang, J.-G. (2020). Edge-terminated $\mathrm{MoS}_{2}$ nanosheets with an expanded interlayer spacing on graphene to boost supercapacitive performance. Chem. Eng. J. 387:124204. doi: 10.1016/j.cej.2020.124204

Wang, H., Min, S., Wang, Q., Li, D., Casillas, G., Ma, C., et al. (2017). Nitrogendoped nanoporous carbon membranes with $\mathrm{Co} / \mathrm{CoP}$ janus-type nanocrystals as hydrogen evolution electrode in both acidic and alkaline environments. ACS Nano 11, 4358-4364. doi: 10.1021/acsnano.7b01946
Wang, J. G., Hua, W., Li, M., Liu, H., Shao, M., and Wei, B. (2018). Structurally engineered hyperbranched $\mathrm{NiCoP}$ arrays with superior electrocatalytic activities toward highly efficient overall water splitting. ACS Appl. Mater. Interfaces 10, 41237-41245. doi: 10.1021/acsami.8b11576

Wang, X., Chen, Y., Yu, B., Wang, Z., Wang, H., Sun, B., et al. (2019). Hierarchically porous $\mathrm{W}$-doped CoP nanoflake arrays as highly efficient and stable electrocatalyst for $\mathrm{pH}$-universal hydrogen evolution. Small 15:1902613. doi: 10.1002/smll.201902613

Wang, Y., Kong, B., Zhao, D., Wang, H., and Selomulya, C. (2017). Strategies for developing transition metal phosphides as heterogeneous electrocatalysts for water splitting. Nano Today 15, 26-55. doi: 10.1016/j.nantod.2017.06.006

Wang, Y., Sun, Y., Yan, F., Zhu, C., Gao, P., Zhang, X., et al. (2018). Self-supported NiMo-based nanowire arrays as bifunctional electrocatalysts for full water splitting. J. Mater. Chem. A 6, 8479-8487. doi: 10.1039/C8TA00517F

Yao, N., Li, P., Zhou, Z., Zhao, Y., Cheng, G., Chen, S., et al. (2019). Synergistically tuning water and hydrogen binding abilities over $\mathrm{Co}_{4} \mathrm{~N}$ by $\mathrm{Cr}$ doping for exceptional alkaline hydrogen evolution electrocatalysis. Adv. Energy Mater. 9:1902449. doi: 10.1002/aenm.201902449

Zhang, G., Wang, B., Bi, J., Fang, D., and Yang, S. (2019). Constructing ultrathin $\mathrm{CoP}$ nanomeshes by Er-doping for highly efficient bifunctional electrocatalysts for overall water splitting. J. Mater. Chem. A 7, 5769-5778. doi: 10.1039/C9TA00530G

Zhang, J., Wang, T., Liu, P., Liao, Z., Liu, S., Zhuang, X., et al. (2017). Efficient hydrogen production on $\mathrm{MoNi}_{4}$ electrocatalysts with fast water dissociation kinetics. Nat. Commun. 8:15437. doi: 10.1038/ncomms15437

Zhang, Y., Gao, L., Hensen, E. J. M., and Hofmann, J. P. (2018). Evaluating the stability of $\mathrm{Co}_{2} \mathrm{P}$ electrocatalysts in the hydrogen evolution reaction for both acidic and alkaline electrolytes. ACS Energy Lett. 3, 1360-1365. doi: 10.1021/acsenergylett.8b00514

Zou, X., and Zhang, Y. (2015). Noble metal-free hydrogen evolution catalysts for water splitting. Chem. Soc. Rev. 44, 5148-5180. doi: 10.1039/C4CS00448E

Conflict of Interest: The authors declare that the research was conducted in the absence of any commercial or financial relationships that could be construed as a potential conflict of interest.

Copyright (C) $2020 \mathrm{Hua}$, Sun, Ren and Nan. This is an open-access article distributed under the terms of the Creative Commons Attribution License (CC BY). The use, distribution or reproduction in other forums is permitted, provided the original author(s) and the copyright owner(s) are credited and that the original publication in this journal is cited, in accordance with accepted academic practice. No use, distribution or reproduction is permitted which does not comply with these terms. 